EPJ Web of Conferences 58, 04002 (2013)

DOI: $10.1051 /$ epjconf/20135804002

(C) Owned by the authors, published by EDP Sciences, 2013

\title{
Millennium Tunneling
}

\section{A novel through space and time}

\author{
Alessandra Rossetti ${ }^{1, a}$ \\ ${ }^{1}$ Geology Student at the University of Bologna
}

\begin{abstract}
Imagine that you wake up in a reality that does not really belong to you. This is exactly what happens to Megan Newman, a young American woman, who is not able to recognize anything around herself, not even her image reflected in the mirror. It takes quite a lot of time before the truth comes out from the labyrinth of her mind: the loss of memory is just the terrible consequence of her traveling across parallel universes.
\end{abstract}

\section{The novel}

The story takes place in many different parts of the United States of America (New York City, Flagstaff, Lakewood and Princeton), ending in the Arizona desert area from where it started and will possibly start again.

The idea on which the novel is based relates the existence of parallel universes to human beings' different choices. Surprisingly, this idea may find scientific support in the "Many Worlds Interpretation of Quantum Mechanics" by Everett (1957). But there are several other strange coincidences in the novel of which the writer was not at all aware, two of them concerning the Navajo ancient Native American population, who has a very important role in the novel. The underworlds in the Navajo Creation Legend close resemble parallel universes and the skinwalker creature of the Navajo mythology has an interesting affinity with the soldiers without a face, created by the evil Doctor Kruger. Finally, and also somewhat impressive, the orphanage in which Megan grew up and that she could not find in her new (parallel) universe did actually exist in our real universe two centuries ago, in the same street of New York City and very close to the place chosen for it in the novel.

There are also intentional recurrences in the novel like e.g. the chains which Megan sees everywhere representing human beings' limitations, and number eight due to its similarity to the infinity symbol. This latter one has a crucial role in Millennium Tunneling as it appears always mysteriously connected with Megan Newman's life. It is the shape of the symbol itself to suggest that infinity might be an eternal return. This relates also to the possible origin for the symbol: the ancient Ouroboros sign, depicting a serpent or a dragon which is eating its own tail. The concept of the eternal return is actually one of the keys of Millennium Tunneling reading.

\section{References}

[1] Rossetti A., Millennium Tunneling (Aracne Editrice, Rome, 2012), 1-426

\footnotetext{
ae-mail: alessandra.rossetti6@studio.unibo.it
} 
